\title{
Aerosol optical depth retrieval using ATSR-2 and AVHRR data during TARFOX
}

\author{
J. Pepijn Veefkind, ${ }^{1}$ Gerrit de Leeuw,${ }^{1}$ Philip A. Durkee, ${ }^{2}$ Philip B. Russell,${ }^{3}$ \\ Peter V. Hobbs, ${ }^{4}$ and John M. Livingston ${ }^{5}$
}

\begin{abstract}
Satellite retrieved aerosol optical properties are compared to aircraft measurements for a case study during the Tropospheric Aerosol Radiative Forcing Observational Experiment (TARFOX). Two satellite instruments are used: the Along Track Scanning Radiometer 2 (ATSR-2) and the advanced very high resolution radiometer (AVHRR). The aerosol optical depth in the mid-visible $(0.555 \mu \mathrm{m})$ retrieved from the ATSR-2 data agrees within 0.03 with colocated sunphotometer measurements. Also, the spectral behavior of the aerosol optical depth is retrieved accurately. Good correlation is found between aerosol optical depths for AVHRR channel $1(0.64 \mu \mathrm{m})$ and sunphotometer derived values, but the satellite retrieved values are 0.05 to 0.15 lower. The Ångström wavelength exponent is determined both from the ATSR-2 and the AVHRR data. The ATSR-2 derived Ångström exponents are in good agreement with the values computed from the sunphotometer data. The Ångström exponents determined from AVHRR data show very large variations. Both the ATSR-2 and the AVHRR aerosol optical depth images show a large gradient. Vertical profile data of temperature, relative humidity, and particle scattering indicate that this gradient is probably caused by changes in the dry aerosol properties, rather than a change in the relative humidity.
\end{abstract}

\section{Introduction}

Atmospheric aerosol particles influence the Earth's radiation balance in two ways: by scattering and absorption of the incoming solar radiation (direct effect), and by changing the albedo and lifetimes of clouds (indirect effect). The radiative forcing caused by anthropogenic aerosol particles due to the combined effects is estimated to be in a wide range between -0.4 and $-3.0 \mathrm{~W} / \mathrm{m}^{2}$ on a global scale [Schwartz, 1996]. These estimates are of the same order of magnitude, but of opposite sign, as the radiative forcing by anthropogenic greenhouse gases. The impact of aerosol particles is considered the largest uncertainty in climate modeling.

\footnotetext{
${ }^{1}$ Netherlands Organization for Applied Scientific Research Physics and Electronics Laboratory, The Hague, The Netherlands.

${ }^{2}$ Department of Meteorology, Naval Postgraduate School, Monterey, California.

${ }^{3}$ NASA AMES Research Center, Moffett Field, California.

${ }^{4}$ Department of Atmospheric Sciences, University of Washington, Seattle.

${ }^{5}$ SRI International, Menlo Park, California.
}

Copyright 1999 by the American Geophysical Union.

Paper number 98JD02816.

0148-0227/99/98JD-02816\$09.00
One of the main reasons for this large uncertainty is the lack of data on a global scale. Satellite monitoring can achieve the global coverage and the necessary spatial resolution to measure the inhomogeneous aerosol fields, necessary as input for climate models. The retrieval of aerosol properties from satellite data requires well-calibrated multispectral sensors [Kaufman, 1995]. These sensors should have narrow spectral bands outside the water vapor absorption regions. Most aerosol retrieval studies in the past have used the visible and near-infrared channels of the advanced very high resolution radiometer (AVHRR) [e.g., Durkee et al., 1991; Husar et al., 1997]. The calibration of these channels is a source of uncertainty [Kaufman, 1995], and the spectral information is limited because the AVHRR bands are broad and not sufficiently separated. Also, the nearinfrared channel 2 suffers from severe absorption by water vapor.

The Along Track Scanning Radiometer 2 (ATSR-2) is the first of a series of satellite sensors that are more suitable for aerosol retrieval. These improved sensors require more advanced aerosol retrieval algorithms to fully utilize their potential. For validation of these algorithms, so-called "column" closure experiments are very useful. This was one of the major goals of the Tropospheric Aerosol Radiative Forcing Observational Experiment (TARFOX) [Russell et al., this issue (a)]. TARFOX was an intensive field program dedicated to measure the direct radiative forcing by tropospheric aerosol 
particles. TARFOX was conducted offshore from the eastern United States in July 1996, one of the most polluted regions on the globe.

In this contribution a comparison is presented between the results from an aerosol retrieval algorithm developed at the Netherlands Organizaton for Applied Scientific Research- Physics and Electronics Laboratory (TNO-FEL) [Veefkind and de Leeuw, 1998] and TARFOX data. This algorithm retrieves the spectral aerosol optical depth (AOD) over the ocean. It includes both multiple scattering and the bidirectional reflectance of the ocean surface. The algorithm was designed to be applicable to different sensors. In this paper it is applied to ATSR-2 and AVHRR data.

The ATSR-2 is a radiometer aboard the European ERS-2 satellite, which was launched in April 1995. ATSR-2 has seven spectral bands, four of these bands are potentially useful for aerosol retrieval. The effective wavelengths of these four channels are $0.555,0.659$, 0.865 , and $1.6 \mu \mathrm{m}$. In-flight calibration is performed by measuring the Sun's irradiance during some parts of the orbit. The spatial resolution is approximately $1 \times 1 \mathrm{~km}^{2}$ at nadir. The swath width is $500 \mathrm{~km}$. The ATSR-2 has a dual view: the reflectance is measured at nadir and at approximately $55^{\circ}$ along track. Independent retrievals from the nadir and the forward image compare favorably [Veefkind and de Leeuw, 1998].

The AVHRR has two shortwave channels: one visible and one near-infrared. The effective wavelengths of the visible and near-infrared channels of the AVHRR aboard the NOAA-14 are 0.64 and $0.84 \mu \mathrm{m}$. The spatial resolution is $1.1 \mathrm{~km}^{2}$ at nadir, and the swath width is approximately $2000 \mathrm{~km}$. A detailed description of the AVHRR is given by Kidwell [1997].

The ATSR-2 is more suitable for aerosol retrieval than the AVHRR because it has more channels that cover a wider wavelength region. Also, the in-flight calibration is an advantage. The drawback of the ATSR-2 is the smaller swath width. The swath of the AVHRR is more than four times larger, providing better global coverage. Also, the AVHRR has a long historical database dating back to the late seventies.

The AOD retrieved from ATSR-2 and AVHRR data will be compared to the AOD measured with a sunphotometer mounted on an aircraft. When the aircraft is flying at low altitude, this is one of the most direct ways to validate aerosol satellite retrieval algorithms. Also, aircraft profile data are used together with satellite data to improve the interpretation of AOD images.

\section{Retrieval Algorithm}

A detailed description of the aerosol retrieval algorithm applied to ATSR-2 data is given by Veefkind and de Leeuw [1998]. The algorithm was designed to be applicable to different sensors. Here it will be applied to ATSR-2 and AVHRR data. Specific details for these two sensors are discussed in some detail.
The algorithm applies only to cloud-free scenes over the open ocean. In the visible and near-infrared the reflectance of the ocean outside sunglint areas is low. For weakly absorbing aerosols, the upwelling radiance at the top of the atmosphere (TOA) over such dark surfaces increases with increasing AOD. In fact, there is a nearlinear relationship between the TOA radiance and the AOD [Durkee et al., 1986]. In the following, reflectance will be used instead of radiance. The reflectance $(\rho)$ is defined as $\pi L / F_{0} \cos \theta_{0}$, where $L$ is the radiance, $F_{0}$ is the extraterrestrial solar irradiance, and $\theta_{0}$ is the solar zenith angle. The TOA reflectance contains contributions from scattering in the atmosphere, reflection at the surface, and combinations of atmospheric scattering and surface reflection. To compute the TOA reflectance properly, multiple scattering and the bidirectional reflectances of the ocean should be taken into account. To this end, the satellite measured reflectance is written as the sum of five components [Tanré et al., 1979]:

$$
\begin{array}{r}
\rho=\rho_{a}+T_{\downarrow} \rho_{s, d v r} T_{\uparrow}+t_{\downarrow} \rho_{s, d z f \downarrow} T_{\uparrow}+ \\
T_{\downarrow} \rho_{s, d v f \uparrow} t_{\uparrow}+t_{\downarrow} \rho_{s, \text { sso }} t_{\uparrow}
\end{array}
$$

where $\rho_{a}$ is the path reflectance by aerosols and molecules, $T$ is the direct transmittance along an upward $(\uparrow)$ or downward $(\downarrow)$ path, $t$ is the diffuse transmittance due to forward scattering by aerosols and molecules, and $\rho_{s, d r r}$, $\rho_{s, d i f \downarrow}, \rho_{s, d i f \uparrow}$ and $\rho_{s, i s o}$ describe the bidirectional surface reflection. All contributions in equation (1) depend on the wavelength and on the Sun/satellite geometry.

The first component in equation (1), the path reflectance, is due to atmospheric scattering by aerosols and molecules. The second component is the contribution of light that is reflected at the surface and transmitted along the downward and upward path through the atmosphere. The last three terms are due to combinations of scattering in the atmosphere and reflection at the surface. For the specular (Fresnel) reflecting ocean surface the contribution of these combinations is significant in almost all geometries. Simulations show that ignoring these terms will lead to serious errors in the retrieved AOD.

The ocean albedo is assumed to be the sum of subsurface reflection, reflection on oceanic whitecaps, and specular reflection. For the open ocean the subsurface reflection is a function of the chlorophyll concentration [Morel, 1988]. The reflection by oceanic whitecaps is taken to be a function of the surface wind speed [Koepke, 1984]. The direct contribution of specular reflection to the TOA reflectance is computed using the Cox and Munk [1954] sunglint formulas. A flat ocean surface is assumed for the computation of the diffuse contribution of specular reflection. Simulations show that this will cause only minor errors [Takashima and Masuda, 1985].

Reflectances and transmissions for Rayleigh atmospheres and atmospheres containing both gases and aerosols were calculated as a function of wavelength and 
geometry and stored in look-up tables. These tables were computed using the DISORT multiple scattering code [Stamnes et al., 1988]. The major advantage of using look-up tables in combination with equation (1) is the computational speed, whereas bidirectional reflectance and multiple scattering are accounted for as well.

The first step in the retrieval of the spectral AOD is the correction for absorption by ozone. Next the TOA reflectance for a Rayleigh atmosphere overlying an ocean surface is subtracted from the measured reflectance. For the AVHRR this is followed by a water vapor absorption correction. The water vapor is assumed to be well mixed with the aerosol [Tanré et al., 1992]. The total column water vapor amount is computed using the split-window technique of Dalu [1986]. The reflectance left after subtraction of the contribution from a Rayleigh atmosphere overlying an ocean surface is due to the aerosol. The aerosol is assumed to be an external mixture of an anthropogenic and a sea-salt aerosol type. These two types are based on the Navy Oceanic Vertical Aerosol Model (NOVAM) [Gathman and Davidson, 1993]. The two aerosol types are mixed such that the spectral behavior of the reflectance due to the aerosol best fits the measurements. This assumes that the multiple scattering from a mixture of two aerosol types can be approximated by the weighted average of the reflectance of the two individual modes [Wang and Gordon, 1994]. The spectral AOD is computed for this mixture, assuming a linear relationship between the TOA reflectance and the AOD.

\section{Experiments}

During the TARFOX field campaign, measurements were performed from many different platforms. These included satellite observations from different polar and geostationary satellites, measurements from four aircraft platforms, ground-based observations from a number of different stations, and measurements from two research vessels. Satellite data from two sensors (ATSR2 and AVHRR) will be compared with measurements from the University of Washington (UW) Convair C$131 \mathrm{~A}$ aircraft [Hobbs, this issue]. Below a description is given of some of the measurements that were performed aboard the UW C-131A during TARFOX.

Aboard the UW C-131A was the six-wavelength NASA Ames Airborne Tracking Sunphotometer (AATS-6) [Matsurnoto et al., 1987]. AATS-6 was used to derive the AOD of the column above the aircraft in four bands with center wavelengths $0.380,0.451,0.525$, and 1.021 $\mu \mathrm{m}$, with widths $0.005 \mu \mathrm{m}$. AOD values and uncertainties were derived as described by Russell et al. [1993; this issue (b)]. Light scattering by aerosol particles was measured with two integrating nephelometers: an MRI model 1567 measuring at $0.540 \mu \mathrm{m}$, and an MS Electron three-wavelength nephelometer measuring at $0.450,0.550$, and $0.700 \mu \mathrm{m}$. Both instruments were measuring at low relative humidity. The aerosol size distribution, in the size range between 0.1 and $3.0 \mu \mathrm{m}$ diameter, was measured using a Particle Measuring Systems (PMS) optical counter type PCASP, which was calibrated using latex spheres. During satellite overpasses the UW C-131A flew at low altitude $(\sim 30 \mathrm{~m}$ above the sea surface), thus being able to measure the AOD of (almost) the total column. Also profiles were flown to obtain information on the vertical structure of the atmosphere and the aerosol properties as a function of height.

\section{Results and Discussion}

During the TARFOX field campaign from July 10 to July 31,1996 , the ATSR-2 passed seven times over the area. Unfortunately, the majority of these overpasses were cloud contaminated. On other days there were no low-level flights during the ERS-2 overpass. However, on July 25 , a day with very few clouds, both data from an ERS-2 overpass and from the sunphotometer are available. Results from this day are presented below. First, a brief overview of the synoptic conditions will be given. To validate the ATSR-2 aerosol retrieval algorithm, results will be compared with sunphotometer data. Also AVHRR retrieved AOD will be compared with sunphotometer data. Finally, profile data from the UW C-131A will be used to investigate the observed AOD pattern.

\subsection{Synoptic Situation}

Prefrontal conditions existed over the TARFOX area on July 25,1996 , with southeasterly flow at $3-5 \mathrm{~ms}^{-1}$ due to a $1015 \mathrm{hPa}$ low-pressure center forming inland over the North Carolina/Virginia border. Plate 1a shows the ATSR-2 near-infrared $(0.865 \mu \mathrm{m})$ image of the TARFOX area. A broad area of low clouds associated with an easterly moving low-pressure center is present in the northern part of the area. Some cumuloform cloudiness associated with the dissipating trailing cold front exists in the southern region of the image. Otherwise, the area is generally clear.

\subsection{ATSR-2 Retrieval}

On July 25, 1996, the ERS-2 passed the TARFOX experimental area at 1552 UTC. The aerosol retrieval algorithm was applied to retrieve the spectral AOD from the ATSR-2 data. To identify clear pixels over the ocean, the cloud and land flags provided in the ATSR-2 data product were used. Pixels for which the sunglint reflectance exceeded $1 \times 10^{-2}$ were marked as sunglint contaminated and excluded from further processing. As mentioned above, the ATSR-2 has a dual view capability, providing two images for different viewing angles (forward and nadir) of the same region. The nadir image for July 25, 1996 is contaminated by sunglint. Therefore, only the forward view will be considered. The image for the AOD at $0.659 \mu \mathrm{m}$ is presented in 


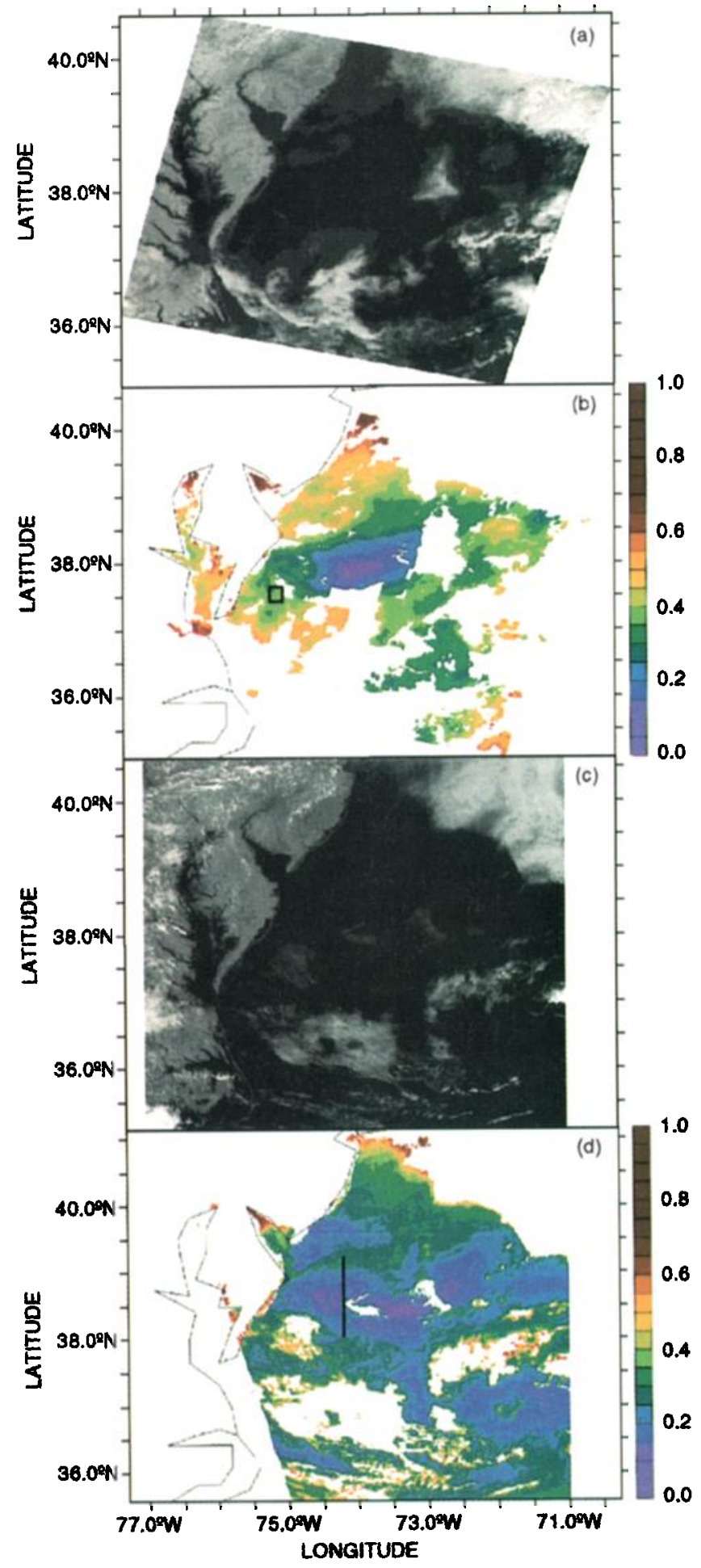

Plate 1. (a) ATSR-2 near-infrared $(0.865 \mu \mathrm{m})$ image for July 25, 1996, 1552 UTC; (b) ATSR-2 retrieved aerosol optical depth at $0.659 \mu \mathrm{m}$ (the box indicates the position of the UW C-131A during the overpass); (c) AVHRR near-infrared $(0.84 \mu \mathrm{m})$ image for July 25 , 1996, 1845 UTC; (d) AVHRR retrieved aerosol optical depth at $0.64 \mu \mathrm{m}$, the UW C-131A flight track is indicated by the black line oriented in a $\mathrm{S}-\mathrm{N}$ direction at $74.2^{\circ} \mathrm{W}$.

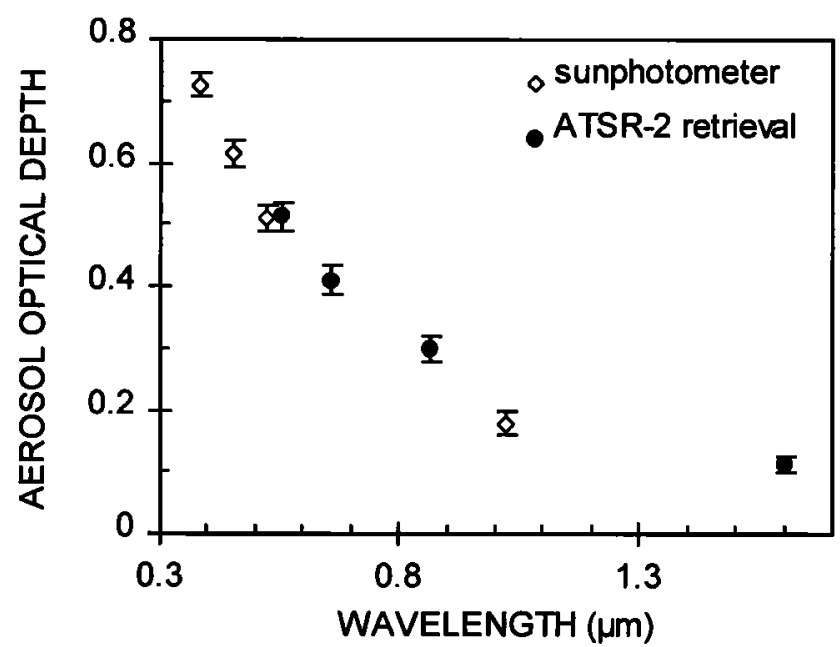

Figure 1. Aerosol optical depth retrieved from ATSR2 data, and aerosol optical depth derived from colocated airborne sunphotometer measurements. Error bars indicate the standard deviation.

Plate 1b. The AOD image shows strong aerosol gradients in the TARFOX area. A region with lower optical depth values $(\sim 0.15$ at $0.659 \mu \mathrm{m})$ is centered around $38^{\circ} \mathrm{N}, 74^{\circ} \mathrm{W}$. North of this region, the AOD increases by a factor of 2-3 over a distance of a few hundred kilometers. To the south and east of the region with lower optical depth, the AOD increases by a factor of 1.5-2. However, there are more clouds present in these regions which makes the interpretation more difficult.

Simultaneous with the ERS-2 overpass, the UW C131A performed a flight track at low altitude (altitude $\sim 30 \mathrm{~m}$ ) (a so-called satellite underflight). The ERS2 underflight was performed between 1544 and 1554 UTC. The position of the aircraft was between 37.4 and $37.6^{\circ} \mathrm{N}$, and 75.2 and $75.0^{\circ} \mathrm{W}$ (see Plate $1 \mathrm{~b}$ ). The sunphotometer aboard the UW C-131A measured the AOD of the total column (minus the lowest $30 \mathrm{~m}$ ). In Figure 1 the mean spectral AOD over the low-altitude track is compared with the AOD retrieved from the ATSR-2 data, averaged over the underflight area. The ATSR2 data and the sunphotometer data are not available at the same wavelengths. However, it is reasonable to assume a smooth variation of the AOD with the wavelength, and thus the data points of both methods can be interpolated. Application of this procedure shows that the ATSR-2 and sunphotometer AOD in the midvisible $(0.555 \mu \mathrm{m})$ compare within 0.03 . Not only is the AOD at this single wavelength retrieved with good accuracy, but the retrieval also reproduces the spectral behavior of the AOD well. The latter contains valuable information on the aerosol size distribution.

The observed AOD is of the order of 0.3-0.7 at 0.659 $\mu \mathrm{m}$ (see Plate $1 \mathrm{~b}$ ). In oceanic background conditions, values of 0.05-0.08 are observed [Veefkind and de Leeuw, 
1998]. The high optical depth observed during TARFOX, together with the strong wavelength dependence (Figure 1), indicates that the aerosol is predominantly of anthropogenic origin.

\subsection{AVHRR Retrieval}

On July 25, the NOAA-14 satellite passed over the TARFOX area at 1845 UTC, almost 3 hours after the ERS-2 pass. For application of the aerosol retrieval to the AVHRR data, the visible and near-infrared channels (channels 1 and 2) were calibrated using postlaunch calibration methods [Rao and Chen, 1996]. To identify cloud-free pixels over the ocean, a very simple empirical land/cloud screening method was used. For every pixel the channel 1 to channel 2 reflectance ratio, $S_{12}$, was computed. All pixels for which $1.5<S_{12}<3.5$ were identified as cloud-free ocean pixels [Wagener et al., 1997]. The same sunglint criteria as for the ATSR2 were applied. The AVHRR near-infrared (channel 2) image together with the retrieved AOD for channel 1 $(0.64 \mu \mathrm{m})$ is shown in Plates 1c and 1d. In general, the AVHRR AOD image (Plate 1d) shows similar features as the ATSR-2 image (Plate 1b). The region with relatively low AOD is also present in the AVHRR image, although less obvious because of the clouds in this region. Also, the observed AOD gradients in the AVHRR image are smaller than for the ATSR-2 retrieval.

During the NOAA-14 pass the UW C-131A aircraft was heading north at low altitude. This AVHRR underflight started at a latitude of $37.6^{\circ} \mathrm{N}$ at $1842 \mathrm{UTC}$ and ended at $38.7^{\circ} \mathrm{N}$ at 1906 UTC. As shown in Plate 1d, the flight track starts in the region with low AOD and passes right through the AOD gradient. Before and after the low-altitude track, the airplane made a vertical profile. For comparison of the AVHRR optical depth with the sunphotometer data, the latter were converted to $0.64 \mu \mathrm{m}$. The AOD can often be represented by a power law function [Angström, 1961]:

$$
A O D(\lambda) \sim \lambda^{-\alpha}
$$

where $\lambda$ is the wavelength and $\alpha$ is the Ångström wavelength exponent.

Such a power law fit was used to convert the sunphotometer data to $0.64 \mu \mathrm{m}$. In Figure $2 \mathrm{a}$ the AVHRR channel 1 (effective wavelength $0.64 \mu \mathrm{m}$ ) AOD is compared with the sunphotometer derived AOD at 0.64 $\mu \mathrm{m}$. The AVHRR AOD is averaged over a small longitude interval between 74.15 and $74.20^{\circ} \mathrm{W}$. Figure 2a shows good correlation between the sunphotometer derived AOD and the AVHRR channel 1 AOD, except for two regions between 37.7 and $38.1^{\circ} \mathrm{N}$. Both peaks in the retrieved AOD in that region are caused by clouds. Outside the cloud-contaminated areas, the trends and features in the data trace very well. Over the whole track the AVHRR retrieved AOD is 0.05-0.15 lower than

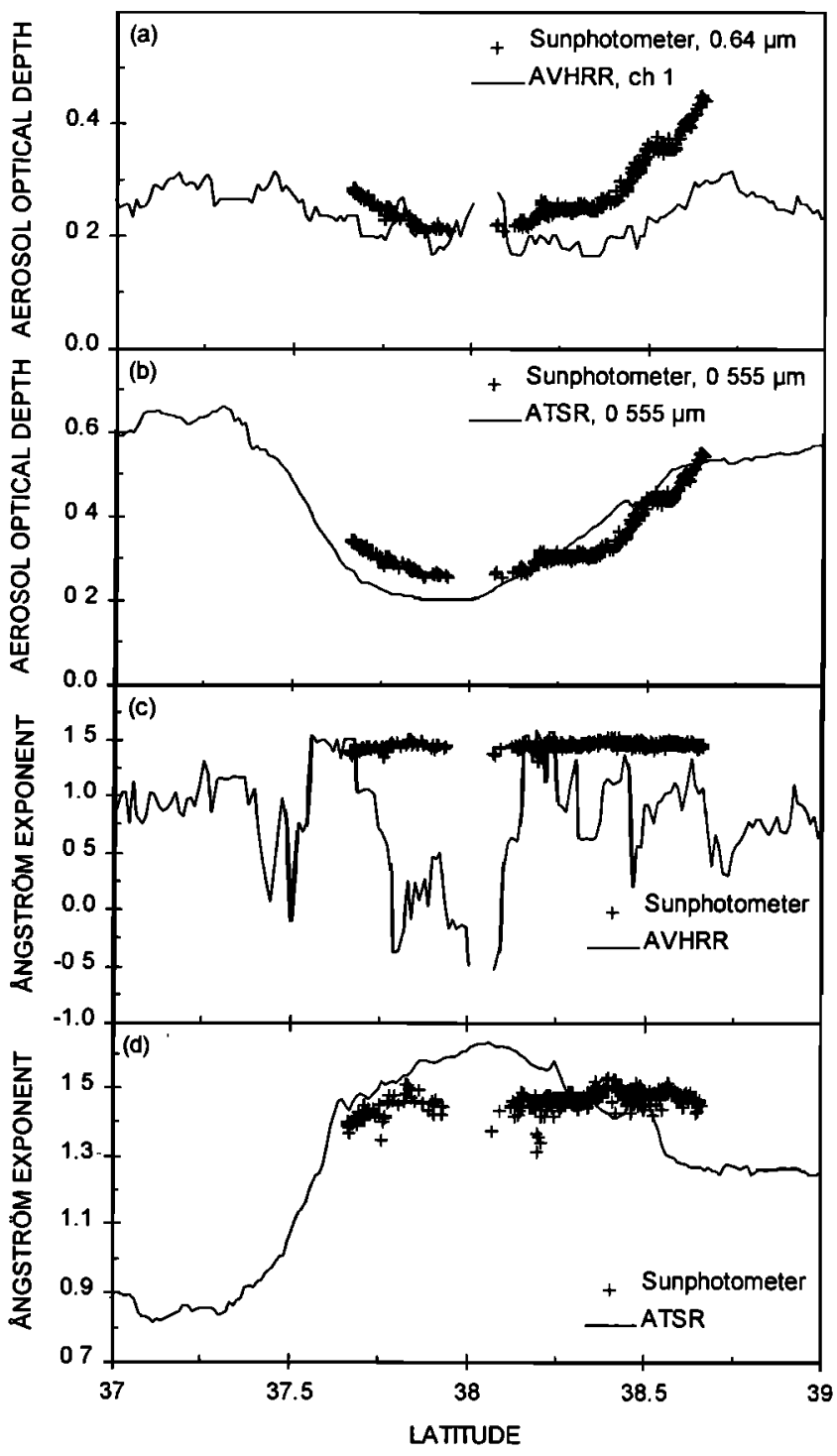

Figure 2. Aerosol optical depth and Ångström wavelength exponent derived from the six-wavelength sunphotometer aboard the UW C-131A, the ATSR-2, and the AVHRR. (a) AVHRR retrieved aerosol optical depth for channel $1(0.64 \mu \mathrm{m})$ and sunphotometer derived aerosol optical depth at this wavelength, plotted as a function of latitude; (b) same as Figure 2a but for ATSR-2 retrieved aerosol optical depth at $0.555 \mu \mathrm{m}$ and sunphotometer derived values at this wavelength; (c) Ångström wavelength exponent derived from AVHRR and from sunphotometer data, plotted as a function of latitude; (d) same as Figure 2c but for the Angström wavelength exponent derived from ATSR-2 and from sunphotometer data.

the sunphotometer derived value. The ATSR-2 data and the size distributions measured with the PCASP on board the UW C-131A indicated that the aerosol was of anthropogenic origin. When the aerosol type in the AVHRR retrieval was fixed to the anthropogenic type, 
the difference between the retrieval and sunphotometer derived values was $<0.1$.

Despite the 3 hour timespan between the ATSR-2 and AVHRR overpass, the AOD patterns (Plates $1 \mathrm{~b}$ and 1d) compare well. Therefore it is interesting to compare the ATSR-2 retrieval with the sunphotometer data measured 3 hours later. Figure $2 \mathrm{~b}$ compares the retrieved ATSR-2 AOD at $0.555 \mu \mathrm{m}$ with the sunphotometer derived value at this wavelength. To take into account the consequences of advection, the retrieved AOD was averaged between 73.5 and $74.5^{\circ} \mathrm{W}$. The difference between the ATSR-2 retrieval and the sunphotometer derived values is $<0.1$ over the entire flight track. In the center of the region with low optical depth, the ATSR-2 AOD is somewhat lower. This difference might be caused by the 3 hour timespan between the airplane and the satellite measurement. Also, the ATSR-2 retrieval was averaged over a large area, whereas the sunphotometer measures along one single track.

The spectral behavior of the AOD depends strongly on the aerosol size distribution. The Angström wavelength exponent $\alpha$ (equation (2)) is related to the slope of the particle size distribution. When $\alpha$ increases, this indicates that the aerosol optical properties are increasingly dominated by particles smaller than the wavelength. When large particles dominate the aerosol optical properties, the Angström wavelength exponent tends toward zero. In Figure 2d the Ångström wavelength exponent derived from the sunphotometer's 0.525 and $1.021 \mu \mathrm{m}$ channels is plotted as a function of the latitude, together with the Angström wavelength exponent computed from the ATSR-2 0.555 and $0.865 \mu \mathrm{m}$ channels. The ATSR-2 data were averaged over the same longitude range as in Figure 2b. The absolute values of the sunphotometer and ATSR-2 Ångström wavelength exponent are in good agreement. At low latitude, the sunphotometer data seem to follow the trend in the ATSR-2 data. For higher latitudes the sunphotometer data seem to be fixed around 1.5, whereas the ATSR-2 Ångström wavelength exponent decreases. The retrieved AOD (Figure 2b) and the retrieved Ångström wavelength exponent (Figure 2d) are strongly anticorrelated. These figures show that when the AOD is at its maximum, the Angström wavelength exponent is at its minimum, and vice versa. This observation indicates that in this case at low AOD the aerosol slope of the size distribution is steeper (relatively more small particles) than at higher AOD.

In Figure 2c the Ångström wavelength exponent derived from the AVHRR retrieval is plotted together with the sunphotometer derived data. The AVHRR derived values for the Angström wavelength exponent clearly show large variations. This variability is caused by the lack of spectral information due to the wide spectral bands of the AVHRR, and the large digitization step, especially in channel 2 .

\subsection{Aerosol Optical Depth Gradient}

AOD gradients as observed in Plate $1 \mathrm{~b}$ and $1 \mathrm{~d}$ can be caused by a difference in the "dry" aerosol properties, by a difference in relative humidity, or by a combination of these effects. Most aerosol particles are hygroscopic; they accrete water when the relative humidity increases. Therefore the scattering coefficient (and thus the AOD) also increases with increasing relative humidity. A change in the dry aerosol properties includes all changes in concentration, size distribution, and chemical composition, except changes due to relative humidity. The question is whether it is possible to distinguish whether an AOD gradient is due to a change in the dry aerosol properties or due to a change in the relative humidity.

To investigate the nature of the optical depth gradient, the UW C-131A vertical profile data were used. As mentioned above, two profiles were measured around the time of the AVHRR overpass, one in the region with low AOD (profile 1), and one in the region with high optical depth (profile 2). Profile 1 was measured from $750 \mathrm{~m}$ down to the surface near $37.9^{\circ} \mathrm{N}, 74.4^{\circ} \mathrm{W}$, and profile 2 from the surface up to about $2.5 \mathrm{~km}$, near $38.6^{\circ} \mathrm{N}, 74.2^{\circ} \mathrm{W}$. The ratio between the AOD for the profile 2 area to the profile 1 area, as derived from the sunphotometer data, is $1.7 \pm 0.1$ at $0.550 \mu \mathrm{m}$. The potential temperature and relative humidity for the two profiles are shown in Figures $3 a$ and $3 b$, respectively. Both profiles show a mixed layer depth of approximately $250 \mathrm{~m}$. The relative humidity in this layer is about $85 \%$. Above this mixed layer the atmosphere is stable. In Figure $3 c$ the dry aerosol scattering coefficient as a function of height is presented. In the mixed layer the dry scattering coefficient is relatively low and con-

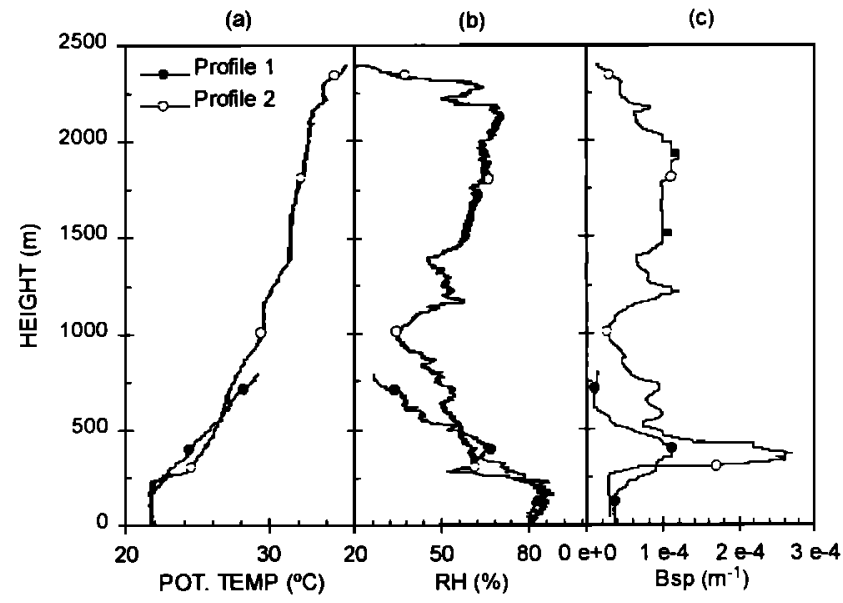

Figure 3. Comparison between profile 1 (near $37.8^{\circ} \mathrm{N}$, $74.4^{\circ} \mathrm{W}$ ) and profile 2 (near $38.6^{\circ} \mathrm{N}, 74.2^{\circ} \mathrm{W}$ ). (a) Potential temperature plotted as a function of height; (b) relative humidity as a function of height; and (c) the dry aerosol scattering coefficient $\left(B_{s p}\right)$ at $0.550 \mu \mathrm{m}$ plotted as a function of height. 
stant with height. Just above this layer there is a strong peak in the dry scattering coefficient. This peak is much stronger for profile 2 than for profile 1 . Above this maximum the scattering coefficient is still higher than in the mixed layer. This vertical aerosol distribution can be explained by a mixed layer of marine origin, with layers containing anthropogenic aerosol at altitudes aloft. The dry AOD between the surface and $790 \mathrm{~m}$ for profiles 1 and 2 was computed by integrating the dry scattering coefficient. The ratio between the AODs in this layer for profiles 2 and 1 is $2.0,1.9$, and 1.7 for $0.450,0.550$, and $0.700 \mu \mathrm{m}$, respectively. These numbers are similar to the AOD ratio of $1.7 \pm 0.1$ at $0.550 \mu \mathrm{m}$, as derived from the sunphotometer. The relative humidity profiles are very similar, and thus cannot explain a $70 \%$ higher total AOD for profile 2. Therefore the observed AOD gradient is likely due to a change in the dry aerosol properties. It is noted that only a small part of the AOD is in the layer below $790 \mathrm{~m}$ (see Figure 3c). Unfortunately, we have no data above $790 \mathrm{~m}$ to support this conclusion.

\section{Conclusions}

AOD retrieved from satellite data have been compared to aircraft sunphotometer data. The data were obtained on the eastern seaboard of the United States on July 25, 1996. Aerosol retrieval using ATSR-2 data compares very well with colocated measurements of an airborne sunphotometer. In the mid-visible the difference between the ATSR-2 retrieval and the sunphotometer values was $<0.03$. Also the spectral behavior of the AOD was retrieved accurately. The latter contains valuable information on the aerosol size distribution. AVHRR retrievals for the same day were somewhat more problematic. The AOD for AVHRR channel 1 $(0.64 \mu \mathrm{m})$ correlated well with the sunphotometer data, but the absolute values of the satellite retrieval were 0.05 to 0.15 lower. The Ångström wavelength exponent was determined from both the ATSR-2 and AVHRR. The ATSR-2 derived values are in good agreement with the values from the sunphotometer. The Angström exponent determined from the AVHRR shows very large variations, caused by the lack of spectral information due to the wide spectral bands, and the large digitization steps in the data.

Both the ATSR-2 and the AVHRR retrieval showed a strong horizontal aerosol gradient. These gradients could have been caused by either a change in the relative humidity or changes in the dry aerosol properties. To investigate the nature of the aerosol gradient, aircraft profile data of temperature, relative humidity, and (dry) aerosol scattering coefficient were used. It was concluded that the aerosol gradient was likely due to changes in the dry aerosol properties.
Acknowledgments. The work described in this paper is supported by the Netherlands Space Research Foundation (SRON), contract EO-008. The ATSR-2 data were kindly provided by the European Space Agency (ESA-ESRIN), contract NL-108. The University of Washington contribution to this study was supported by NSF grants ATM9412082 and ATM-9408941, and the NASA EOS SAGEIII Science Program. This research was conducted as part of the Tropospheric Aerosol Radiative Forcing Observational Experiment (TARFOX), which is a contribution to the International Global Atmospheric Chemistry (IGAC) core project of the International Geosphere-Biosphere Programme (IGBP). Financial support for the measurements and analyses was provided by the U.S. National Aeronautics and Space Administration and the U.S. National Science Foundation. The authors like to thank Robert Koelemeijer of the Royal Netherlands Meteorological Institute (KNMI) for his help with the ATSR-2 data. Part of the work described here was performed while J.P. Veefkind was visiting the Naval Postgraduate School, Department of Meteorology. The Ferret analysis package was used in the preparation of this work (available at http://ferret.wrc.noaa.gov/).

\section{References}

Ångström, A., Techniques of determining the turbidity of the atmosphere, Tellus, 13, 214-223, 1961.

Cox, C., and W. Munk, Statistics of the sea surface derived from sun glitter, J. Mar. Res., 13, 198-227, 1954.

Dalu, G., Satellite remote sensing of atmospheric water vapour, Int. J. Remote Sens., 7, 1089-1097, 1986.

Durkee, P.A., D.R. Jensen, E.E. Hindman, and T.H. Vonder Haar, The relationship between marine aerosol particles and satellite detected radiance, J. Geophys. Res., 91, 4063-4072, 1986.

Durkee, P.A., F. Pfeil, E. Frost and R. Shema, Global analysis of aerosol particle characteristics, Atmos. Environ., $25 A, 2457-2471,1991$.

Gathman, S.G. and K.L. Davidson, The Navy Oceanic Vertical Aerosol Model, NRAD Tech. Rep. 1634, 107 pp., NRAD, San Diego, Calif., 1993.

Hobbs, P.V., An overview of the University of Washington airborne measurements and results from the Tropospheric Aerosol Radiative Forcing Observational Experiment (TARFOX), J. Geophys. Res., this issue.

Husar, R.B., J.M. Prospero, and L.L. Stowe, Characterization of tropospheric aerosols over the oceans with the NOAA advanced very high resolution radiometer optical thickness operational product, J. Geophys. Res., 102 (D14), 16,889-16,909, 1997.

Kaufman Y.J., Remote sensing of the direct and indirect aerosol forcing, in Aerosol Forcing of Climate, edited by R.J. Charlson and J. Heintzenberg, pp. 297-332, John Wiley, New York, 1995.

Kidwell, K.B., NOAA polar orbiter data users guide, Aug. 1997 revision, Natl. Oceanic and Atmos. Admin., Silver Spring, Md., 1997. (Available at http://www2.ncdc.noaa. gov/docs/podug)

Koepke, P., Effective reflectance of oceanic whitecaps, Appl. Opt., 23, 1816-1824, 1984.

Matsumoto, T., P.B. Russell, C. Mina, and W. Van Ark, Airborne tracking sunphotometer, J. Atmos. Oceanic Technol., 4, 336-339, 1987.

Morel, A., Optical modeling of the upper ocean in relation to its biogenous matter content (case I waters), J. Geophys. Res., 93 (C9), 10,749-10,768, 1988. 
Rao, C.R.N, and J. Chen, Post-launch calibration of the visible and near-infrared channels of the advanced very high resolution radiometer on the NOAA-14 spacecraft, Int. J. Remote Sens., 17, 2743-2747, 1996.

Russell, P.B., J.M. Livingston, E.G. Dutton, R.F. Pueschel, J.A. Reagan, T.E. DeFoor, M.A. Box, D. Allen, P. Pilewskie, B.M. Herman, S.A. Kinne and D.J. Hofmann, Pinatubo and Pre-Pinatubo Optical Depth Spectra: Mauna Loa Measurements, Comparisons, Inferred Particle Size Distributions, Radiative Effects, and Relationship to Lidar Data, J. Geophys. Res., 98, 22,969-22,985, 1993.

Russell, P.B., P.V. Hobbs, and L.L. Stowe, Aerosol properties and radiative effects in the U.S. east coast haze plume: An overview of the Tropospheric Aerosol Radiative Forcing Observational Experiment (TARFOX), J. Geophys. Res., this issue (a).

Russell, P.B., J.M. Livingston, P. Hignett, S. Kinne, J. Wong, A. Chien, R. Bergstrom, P. Durkee, and P.V. Hobbs, Aerosol-induced radiative flux changes off the United States mid-Atlantic coast: Comparison of values calculated from sunphotometer and in situ data with those measured by airborne pyranometer, J. Geophys. Res., this issue (b).

Schwartz, S.E., The whitehouse effect- shortwave radiative forcing of climate by anthropogenic aerosols: an overview, J. Aerosol Sci., 27, 359-382, 1996.

Stamnes, K., S. Tsay, W. Wiscombe, and K. Jayaweera, Numerically stable algorithm for discrete-ordinate-method radiative transfer in multiple scattering and emitting layered media, Appl. Opt., 27, 2502-2509, 1988.

Takashima, T., and K. Masuda, Degree of radiance and polarization of the upwelling radiation from an atmosphereocean system, Appl. Opt., 24, 2423-2429, 1985.

Tanré, D., M. Herman, P.Y. Deschamps, and A. De Leffe, Atmospheric modeling for space measurements of ground reflectances including bidirectional properties, Appl. Opt., 18, 3587-3594, 1979.

Tanré, D., B.N. Holben, and Y.J. Kaufman, Atmospheric correction for NOAA-AVHRR products: Theory and application, IEEE Trans. Geosci. Remote Sens., 30, 231$248,1992$.

Veefkind, J.P., and G. de Leeuw, A new aerosol retrieval algorithm to determine the spectral aerosol optical depth from satellite radiometer measurements, J. of Aerosol Sci., 29, 1237-1248, 1998.

Wagener, R., S. Nemesure, and S.E. Schwartz, Aerosol optical depth over oceans: High space and time resolution retrieval and error budget from satellite radiometry, $J$. Atmos. Oceanic Technol. 14, 577-590, 1997.

Wang, M., and H.R. Gordon, Radiance reflected from the ocean-atmosphere system: synthesis from individual components of the aerosol size distribution, Appl. Opt., 33, 7088-7095, 1994.

G. de Leeuw and J. P. Veefkind, TNO Physics and Electronics Laboratory (TNO-FEL), P.O. Box 96864, NL2509 JG The Hague, The Netherlands. (deleeuw@fel.tno.nl; veefkind@fel.tno.nl)

P. A. Durkee, Department of Meteorology, Naval Postgraduate School, 589 Dyer Road, Monterey, CA 93943-5113.

P. V. Hobbs, Department of Atmospheric Sciences, University of Washington, PO-Box 351640, Seattle, WA 981951640.

J. M. Livingston, SRI International, Menlo Park, CA 94025.

P. B. Russell, NASA Ames Research Center, MS 245-5, Moffett Field, CA 94035-1000.

(Received January 30, 1998; revised August 17, 1998; accepted August 17, 1998.) 